\title{
Impact of the Built Environment on Mental and Sexual Health: Policy Implications and Recommendations
}

\author{
David Satcher, Martha Okafor, and LeConté J. Dill \\ The Satcher Health Leadership Institute, Morehouse School of Medicine, 720 Westview Drive, SW NCPC 238, Atlanta, \\ GA 30310, USA \\ Correspondence should be addressed to Martha Okafor, mokafor@msm.edu
}

Received 22 March 2012; Accepted 19 April 2012

Academic Editors: H. Balcazar and C. Banwell

Copyright ( 92012 David Satcher et al. This is an open access article distributed under the Creative Commons Attribution License, which permits unrestricted use, distribution, and reproduction in any medium, provided the original work is properly cited.

Research related to the intersection of the built environment and health has particularly flourished in the last decade. The authors highlight the theoretical and policy insights that have been made while also noting paucity in this literature as specifically related to mental and sexual health. Overall, the authors discuss policy implications of aspects of the built environment on both mental and sexual health behaviors and outcomes and suggest avenues for future research, program implementation, and policymaking for advancing health equity in these areas.

\section{Introduction}

The built environment has been defined as "all buildings, spaces, and products that are created and modified by humans" [1]. Connections between the built environment and health can be traced back at least to Hippocrates' work On Airs, Waters and Places initially published more than 2600 years ago [2]. By studying the living conditions of populations in Europe and Asia, Hippocrates, a physician, asserted that human health and illness were associated with a desirable state of equilibrium between the human organism and his or her immediate environment [2]. In the United States, social science scholar and activist W. E. B. Du Bois established that health was a function of living conditions [3]. In particular, Du Bois' research illuminated the impact that urban planning decisions have on the most vulnerable populations in our society, namely, the very young, the poor, and people of color [3]. These vulnerable populations fare the most disproportionately in their health outcomes from untimely decision making and inaction on issues related to the built environment. In the 19th and early 20th centuries, issues related to the built environment were focused on sanitation, workplace safety, fire codes, lead abatement, access for people with disabilities, and other efforts to specifically combat communicable diseases. The 21 st century is an opportunity for decisions related to the built environment to address the nation's greatest current public health concerns, including obesity, cardiovascular disease, diabetes, asthma, injuries, violence, mental illness, substance abuse, sexual assault, and social inequities.

Core areas of the built environment include land use, zoning, buildings, transportation systems, services, and public resources. Land use refers to the ways in which specific parcels of land and areas within communities are used [4]. Mixed use is a term to describe more than one type of land use in a given location (i.e., a business with an apartment above it). Zoning refers to the hierarchical order of these land uses [5]. Zoning was initially intended to protect people from certain exposures but has manifested to currently often separating people from the critical services and resources that they need. Overall, zoning impacts the buildings in communities, including residences, schools, and churches. Transportation systems, including roads, highways, and public transit systems, increase access between different zones but also have contributed to rapid suburbanization and sprawl. Sprawl is a multifaceted concept, which includes the spreading outwards of a city and its suburbs to lowdensity, autodependent, and land-use-segregated rural areas through development decisions and practices $[4,6]$. Services include shopping centers, grocery stores, banking centers, 
healthcare facilities, recreation centers, and waste transfer centers. Low-income neighborhoods and communities of color typically have fewer grocery stores and more convenience stores, liquor stores, and fast-food restaurants selling cheaper, high-fat foods, contributing to food deserts and disparities in overweight and obesity $[7,8]$. Public resources in communities include parks, libraries, and museums. Overall, these core components of the built environment do not act independently, but their interactions greatly impact the health and well-being of individuals and communities.

Elements of the built environment can create conditions for either positive or negative social determinants of health. To-date, most of the current research on the built environment focuses on its impact on nutrition and physical activity [9]. Mental health and sexual health are also critical components of functional well-being. The impact of the built environment, specifically as it relates to mental and sexual health, deserves more thoughtful research.

\section{The Built Environment and Mental Health}

Neighborhoods characterized by blighted housing, lack of greenspace, minimal or lack of public transportation, lack of services and resources such as grocery stores, libraries, and recreation centers, high rates of violence and crime, and limited access to quality healthcare facilities are perceived as negative determinants of health [10]. Evidence has shown that people who live in such neighborhoods have unequal distribution, acquisition, and utilization of resources leading to unequal hardships, deprivation of opportunities, and a higher burden of diseases [11].

According to the USA Surgeon General's Report on Mental Health [12], mental health is fundamental to physical health and overall health. Mental health contributes to personal well-being, family and interpersonal relationships, and functional ability of a community or society. Depression is the most common mental illness. Depression is the third leading cause of the global disease burden worldwide and the leading cause of disease burden in both middle and higher income countries [13]. Depression is associated with unhealthy relationships, reduced quality of life and social functioning, and the leading cause of excess disability. Similarly, anxiety is one of the most frequently occurring mental disorders. Anxiety may provoke emotional responses, such as, intense fear or dread, as well as physical responses, such as, rapid heartbeat and perspiration [12]. According to the Substance Abuse and Mental Health Services Administration 2010 USA National Report, an estimated 9.8 million adults aged 18 or older had a serious mental illness, and 2 million youth aged 12 to 17 years had a major depressive episodes during the year of 2008 [14]. Also, it is estimated that by 2020 , behavioral health disorders will surpass all physical diseases as a major cause of disability worldwide [15]. However, it is crucial to note that treatment for mental illness is effective and people can recover from this illness. Existing research reveals that stigma, defined as an attribute that is deeply discrediting to an individual, prevents people living with mental illness from seeking care, influences what services are sought, and determines when and where people seek care and services [12, 16-19]. Stigma also impacts how treatment is delivered and how people living with mental illness are perceived and treated in the community. It is clearly established that individual and public perceptions of mental health affect how people living with mental illness construct and interpret their identities. It also impacts how we zone places to locate mental health treatment facilities, which in turns affects availability and accessibility of treatment. Recently, the integration of mental health and primary healthcare has improved access and reduced stigma.

Many studies have focused mainly on built environment's impact on physical health. Meanwhile, the disabling effects of behavioral health disorders can worsen chronic physical health conditions and disrupt a person's ability to comply with treatment regimen, carry out daily activity and work, to mention just a few reasons. There are few studies that have examined the impact of social environments on mental health [20], and fewer studies focused on the built environment's impact on mental health [21-23]. Emerging research has established the association between neighborhood environments and mental health, particularly depression [22-25]. Findings from the existing limited studies have shown that housing density, greenspace, land use, and transportation are associated with depressive symptoms. According to Miles et al. [20] in a study of Miami residents, people who live in neighborhoods with higher housing density, more mixed land use, larger acreage of greenspace, and lower exposure to chronic noises from vehicular burdens have relatively lower depressive symptoms than people not experiencing these specific built environmental conditions. This study also shows that the ways in which residents use their environment matters [20]. Emerging literature on mental health recovery also suggests that greenspace, including parks, and access to healthcare within walking distance to such greenspace contribute positively to the recovery of people living with mental illness [26-28]. These studies indicate that the physical environmental conditions that provide sense of identity, safety, security, and social connection or networks to people living with mental illness improve their recovery in the community. Kirkpatrick and Byrne's [29] study shows that "good housing" is linked to faster recovery and is associated with safety, privacy, protection, and control. In addition, it is clear from their research that social and supportive networks are essential to recovery [29]. With one in four adults in the USA suffering from a diagnosable mental disorder each year, it is clear that people do recover from this disorder and live in our communities $[30,31]$. People in recovery from mental illness work, pay taxes, have homes and relationships, volunteer, vote, and contribute to the community where they live. Therefore, one could link the characteristics of built environment that facilitate walkability, safety, access to employment centers, and connection to positive peer and other social networks to positive health behaviors and outcomes. Whitley and Prince [32] suggest that built environment for a recovery community should not reflect a typical urban environment with high density of car usage, noises from vehicles, limited greenspace, limited walkability, and stressors that facilitate 
insecurity and sense of danger. When one is exposed to social isolation and neighborhood vehicular noises from overdependency on automobile usage, these conditions increase the risks of mental disorder, particularly depression [24]. Rather, the recovery community needs characteristics in the built environment that support walking and opportunities for meeting neighbors, socializing, and conducting daily errands without driving. Other recent studies show that having pedestrian walking and biking routes and community services and resources located within walking distance for residents encourages walking, cycling, and biking as means of running daily routine activities, thus increasing social interactions in the neighborhoods while reducing social isolation and depressive symptoms [33-36]. Such literature has shown that conditions that support walkability and social connections have protective effects on people's mental health by increasing individual hope and trust and fostering social cohesion among community members. Findings from these studies suggest that the relationship between identity and mental health may be associated with the usage of built environment and services.

Research findings suggest that positive neighborhood environments are related to positive determinants of mental health, such as, parks for walking, while negative neighborhood environments are related to negative determinants of mental health, such as, stressors from chronic exposure to car traffic and noises [20]. Also, studies have shown that living in a neighborhood with disproportionate high burden of autocommuters relative to land area was associated with more depressive symptoms than living in areas with lower autocommuter density [37]. As a result, places where the zoning permits mixeduse of the land for both residential and commercial purposes with conditions that promote walkability are emerging as preferred options for people living in the urban areas. The preference of mixed use over single use permits the building of residential housing, schools, churches, and businesses in a community with varied transportation systems and roads with routes for automobiles and pedestrian walking, highways, if applicable, built-in parks, open greenspace, libraries, and museums. Such positive conditions of health, including mental health, are largely determined by zoning and land use decisions and policies, which are features of the built environment.

\section{The Built Environment and Sexual Health}

The term "riskscapes" has been applied to high-risk, lowincome geographic settings that have a disproportionate burden of inequitable planning and zoning, neighborhood stressors, unhealthy land uses, and limited access to healthpromoting resources, such as, medical facilities, grocery stores, parks, open spaces, and healthy schools $[38,39]$. Typically used in the environmental health and environmental justice literature, riskscapes leave low-income communities and communities of color vulnerable to the effects of environmental hazards, air pollution, urban decay, manmade and natural disasters, and climate change. Distressed neighborhoods, or riskscapes, are typically characterized by physical incivilities (e.g., vandalism, graffiti, and debris) and social incivilities (e.g., noise, prostitution, drug trafficking, and gang-related activity) [40, 41].

Riskscapes can also be examined for their impact on sexual health. A comparatively small but growing body of literature has examined the effect of the built environment, namely, "neighborhood effects," on sexual behaviors and health outcomes [42-44]. Distressed neighborhoods have an absence of a safe and accessible recreational spaces, particularly for older adolescents [42-44]. A focus is placed on adolescents because they bear an unequal burden of adverse sexual health outcomes resulting in significant social and financial costs [45]. Researchers have found that adolescents living in these riskscapes experience disproportionately higher rates of early sexual initiation, multiple sex partners, sexually transmitted infections (STIs), unintended pregnancies, sexual assault, and lower rates of contraceptive use [42-44, 46, 47]. In a qualitative study of adolescents and young adults living in two rural communities, Akers et al. [42] found that the lack of safe and well-maintained recreational facilities in neighborhoods mediated sexual and other risk behaviors. Adolescents and young adults interviewed in this study shared that their neighborhood lacked key services and resources of the built environment that they desired, such as, bowling alleys, movie theaters, skating rinks, and museums. Consequently, they viewed the lack of recreational opportunities in their neighborhood environments as mediators for risky behaviors in general, including sexual risk behaviors. The limited studies in this area suggest that the lack of recreational spaces for young people, as well as the very limited community monitoring by adults or authority figures at the few recreational sites that do exist in communities create opportunities for sexual activities, which oftentimes become risk-taking activities.

Lang et al. [47] cross-sectional study of sexual risk behaviors among adolescents diagnosed with psychological disorders in three USA urban cities is the first published study to report that high-risk neighborhood environments (e.g., presence of broken bottles and trash and prominence of abandoned buildings and vacant lots) are associated with increased prevalence of laboratory-confirmed STIs among adolescents. The authors found that neighborhood environment was a valid proxy for adolescents' risk of acquiring STIs. Admittedly, more research is needed to further investigate the specific mechanisms by which neighborhood environments affect sexual risk taking, but the authors posit that some adolescents may partake in risky sexual behaviors as a coping mechanism against stressors in their environments.

Additionally, the concentration of abandoned properties and public and private disinvestment has not been well investigated specifically in relationship to the growing public health epidemic of sexual assault, specifically the commercial and sexual exploitation of children (CSEC). This intersection of the impact of the built environment on sexual exploitation and assault is ripe for further inquiry.

Girls, in particular, face specific environmental threats because of their gender, including sexual harassment, pressure toward early sexual initiation, intimate partner violence, and sexual assault [48]. "Female fear" is a term used to 
describe the fear of sexual victimization, verbal and physical assault, and sexual exploitation that girls and women experience $[48,49]$. Female residents in high-poverty, socially isolated neighborhoods are at greater risk of sexual assault, particularly those living in public housing [48, 50]. Girls learn to use complex, yet effective strategies to remain safe in such environments [48]. The findings from this study further support the need for more research on the specific neighborhood-level risks that may affect young girls more likely than boys.

The neighborhood environment can also place undue physical and social stressors on the human body and on people's ability to access resources, particularly for those experiencing infectious diseases [51, 52]. As related to Human Immunodeficiency Virus (HIV) and Acquired Immunodeficiency Syndrome (AIDS), the provision of and access to appropriate treatment may be unequally distributed by neighborhood [51]. The Centers for Disease Control and Prevention (CDC) have reported that $2.1 \%$ of heterosexuals living in high-poverty urban areas in the United States is infected with HIV, a rate well above the 1\% that illustrates an overall epidemic [53]. Additionally, the CDC identifies poverty as "the single most important demographic factor associated with HIV infection among inner-city heterosexuals" [53].

The built environment, even in the most distressed contexts, does not only represent health-comprising settings. Neighborhoods have been found to be important for fostering social networks that can influence health-related behaviors, attitudes, and norms [51, 52]. Additionally, research suggests that residents of neighborhoods with abundant institutional resources are more likely to experience improved health and social outcomes [54-57]. Hospitals, schools, recreation centers, and shelters are some of the institutional assets found in neighborhoods. Such institutions can buffer the aforementioned macrostructural forces of poverty, racism, sexism, and homophobia that tend to negatively affect sexual health outcomes. As related to the HIV/AIDS epidemic, traditional AIDS service organizations (ASOs), health clinics, and less-conventional intervention settings, such as, churches, beauty salons and barbershops, and, in some instances, prisons, can offer the most effective prevention and treatment services [58]. Similarly, the presence of safe havens (e.g., after-school programs and recreation centers) in communities can combat youth's idle time and support youth in resisting risky sexual behaviors $[48,59,60]$.

\section{Policy Implications}

It is vital to link the built environment to mental health and sexual health because both mental health and sexual health are fundamental components to health and human functioning. With the emerging discussions of the importance of place to the health of individuals and communities, a deeper analysis of the interactions between the built environment and the mental and sexual health behaviors and outcomes is warranted.
There are policy changes that have taken place in recent years leading to positive mental and sexual health. An example of such policy changes was enacted in 1978 and made it illegal to use lead-based paint on the inside of housing. Prior to this policy change, many children, especially infants and toddlers, were suffering brain damage because of their ability to eat chipped lead-based paint inside the house. Since the enactment of this policy outlawing lead-based paint indoors, we have seen a dramatic decline in the number of children suffering lead toxicity and brain damage. Also, there has been a remarkable decline in blood lead levels in this country, from about 10 micrograms per deciliter to now around two micrograms per deciliter.

More understanding of the association between built environment and mental health is important for public health as we aim to elucidate the benefits of specific built environmental conditions in urban, suburban, and rural neighborhoods and apply these benefits as protective factors against the stressors of living in any of such types of neighborhoods.

Perhaps one of the most impactful policy changes that has led to positive environment impacting mental and sexual health of many neighborhoods is the "policing" policy. This policy requires police to be more present and visible in cities and other communities. Several communities now have community policing where police walk the streets of communities, get to know the children in the community, and help create the environment that is not conducive to either sexual assault or inappropriate sexual behavior on or around the streets of many inner city communities. This community policing creates environments that are much safer, especially for young women and for young people in general. There is a need to further examine how violence and unsafe environment relate to uncontrolled stress, increased fear, isolation, anxiety, and depression and their impacts on mental functioning, work productivity, relationships, and physical health. As research has revealed that social isolation is linked to depression; characteristics of built environment that make it easy for people to walk, interact with one another, socialize, and connect in supportive ways can be promoted to protect the mental health and well-being of the community.

One of the major changes in policies related to the built environment is in the form of zoning laws. Some of these zoning laws have restricted the number of fast food stores or liquor stores that can be present in the community. This restriction in essence decreased the sale of alcohol and tobacco in many communities. The zoning laws have also provided access to fresh fruits and vegetables in some communities that did not have access to such resources in the past. Furthermore, land use regulation could be used to exclude location of stores selling substances, such as, cigarettes, drugs, or alcohol within a reasonable distance from elementary, middle, and high schools. Through policies related to mixed land use, equitable redevelopment, community land trusts, and transit-oriented development, we can explore community-centered efforts to ameliorate neighborhood stressors and promote opportunities for social 
cohesion and access to needed goods and services [6164]. Tax policies can also be used to provide tax credits as incentives to employers to provide employment to residents of the communities where their businesses are located.

In addition, the "Wellness" policy, which the United States' Congress passed in 2004, is another policy change that provided at least one hot meal, usually breakfast, at school for children from low-income households. This policy also required schools to have more time for physical education to take place during the school hours. Such policy interventions have been linked to improved learning, physically fitness, discipline, and academic performance in the classroom. So, we posit that to create a thriving community and productive society, we have to align our decisions related to the built environment to social policies in order to create positive conditions that facilitate mental health and functioning of communities.

Effective programmatic and policy decisions related to the built environment can also influence positive sexual health behaviors and outcomes. From a youth development perspective, "adolescent-friendly design" to places, such as, downtowns, parks, and schools, can be promoted to accommodate teens rather than discouraging them from idly hanging out [65]. These design decisions should allow for secure social interaction and should be incorporated with the broader community's design initiatives to allow for youth's interaction with other community members and to promote healthy adolescent development [65, 66]. From a gender perspective, "safety audits" engage women in assessing current neighborhood safety and identifying mechanisms to enhance safety $[67,68]$. Such audit recommendations can reach a broad audience, including landlords, school official, and legislators. Also, like youth-led planning, women's safety audits reflect a commitment to planning based on local knowledge and expertise $[67,69]$. Overall, we need to devote more research and resources to assess how changes in the built environment can improve sexual health and ultimately impact health equity.

\section{Conclusion}

The importance of both mental health and sexual health to the healthy functioning of human beings has been established $[12,70]$. It is clear that behavior is the final common pathway of multiple influences in one's life and environment, both physical and social. In this paper, we have examined the impact of built environment on mental and sexual health. In order to improve mental health outcomes and sexual health behavior, we must better target the environmental influences and context in which people interact. Therefore, there are transformative leadership opportunities to impact the built environmental implications on mental and sexual health outcomes even in the most distressed contexts. Thoughtful and equitable decision making regarding land use, zoning, buildings, transportation systems, services, and public resources can combat disparities and promote equity in mental and sexual health behaviors and outcomes.
Similar to the World Health Organization's (WHO) Commission on Social Determinants of Health report, it was recommended that policy in the future will be examined for its impact on health [71]. Investing in healthy environments, the report held, was the most cost-effective approach to improving health and preventing disease. Therefore, we must have in place the appropriate built environment policies and practices that promote mental health and healthy sexuality. If we fail to provide the appropriate built environment that give individuals and families the opportunity to lead healthy lives, then we as a society are at fault. This approach is also the most humane approach to health.

\section{References}

[1] J. Grant, M. O'Neill, B. Petersen et al., Our Built and Natural Environments: A Technical Review of the Interactions between Land Use, Transportation, and Environmental Quality, U.S. Environmental Protection Agency, Washington, DC, USA, 2000.

[2] Hippocrates, On Air, Waters and Places, in the Genuine Works of Hippocrates, The Sydenham Society, London, UK, 1849.

[3] W. E. B. Du Bois, Ed., The Health and Physique of the Negro American, Atlanta University Press, Atlanta, Ga, USA, 1906.

[4] A. L. Dannenberg, R. J. Jackson, H. Frumkin et al., "The impact of community design and land-use choices on public health: a scientific research agenda," American Journal of Public Health, vol. 93, no. 9, pp. 1500-1508, 2003.

[5] B. W. Ohm, Guide to Community Planning in Wisconsin, Board of Regents of the University of Wisconsin System, Madison, Wis, USA, 1999.

[6] R. D. Bullard, G. S. Johnson, and A. O. Torres, Eds., Sprawl City: Race, Politics, and Planning in Atlanta, Island Press, Washington, DC, USA, 2000.

[7] J. Mair, M. Pierce, and S. Teret, The Use of Zoning to Restrict Fast Food Outlets: A Potential Strategy to Combat Obesity, The Center for Law and the Public's Health at Johns Hopkins and Georgetown Universities, Washington, DC, USA, 2005.

[8] S. N. Zenk, A. J. Schulz, B. A. Israel, S. A. James, S. Bao, and M. L. Wilson, "Fruit and vegetable access differs by community racial composition and socioeconomic position in Detroit, Michigan," Ethnicity and Disease, vol. 16, no. 1, pp. 275-280, 2006.

[9] S. S. Casagrande, M. C. Whitt-Glover, K. J. Lancaster, A. M. Odoms-Young, and T. L. Gary, "Built environment and health behaviors among African Americans. A systematic review," American Journal of Preventive Medicine, vol. 36, no. 2, pp. 174-181, 2009.

[10] R. Wilkinson and M. Marmot, Social Determinants of Health: The Solid Facts, World Health Organization, Copenhagen, Denmark, 2003.

[11] CDC, "Office of Minority Health," 2011, http://www.cdc.gov/ omhd/amh/factsheets/mental.htm.

[12] D. Satcher, Mental Health: A Report of the Surgeon General, United States Public Health Service, Washington, DC, USA, 1999.

[13] C. E. Ross and D. Hayes, "Exercise and psychologic well-being in the community," American Journal of Epidemiology, vol. 127, no. 4, pp. 762-771, 1988.

[14] Substance Abuse and Mental Health Services Administration (SAMHSA), Results from the 2010 National Survey on Drug Use and Health: Summary of National Findings, National Survey 
on Drug Use and Health series, Substance Abuse and Mental Health Services Administration, Rockville, Md, USA, 2011.

[15] L. Rosenberg, "Mental Health: A Silent Public Health Crisis,” 2011, http://www.huffingtonpost.com/linda-rosenberg/ mental-illness-awareness-week_b_987735.html.

[16] J. Crocker, "Social stigma and self-esteem: situational construction of self-worth," Journal of Experimental Social Psychology, vol. 35, no. 1, pp. 89-107, 1999.

[17] E. Goffman, Stigma: Notes on the Management of a Spoiled Identity, Simon and Schuster, New York, NY, USA, 1963.

[18] B. G. Link and J. C. Phelan, "Conceptualizing stigma," Annual Review of Sociology, vol. 27, pp. 363-385, 2001.

[19] L. Sayce, "Stigma, discrimination and social exclusion: what's in a word?" Journal of Mental Health, vol. 7, no. 4, pp. 331-343, 1998.

[20] R. Miles, C. Coutts, and M. Asal, "Neighborhood urban form, social environment, and depression," Journal of Urban Health, vol. 89, no. 1, pp. 1-18, 2012.

[21] C. Mair, A. V. Diez Roux, and S. Galea, "Are neighbourhood characteristics associated with depressive symptoms? A review of evidence," Journal of Epidemiology and Community Health, vol. 62, no. 11, pp. 940-946, 2008.

[22] S. Galea, J. Ahern, S. Rudenstine, Z. Wallace, and D. Vlahov, "Urban built environment and depression: a multilevel analysis," Journal of Epidemiology and Community Health, vol. 59, no. 10 , pp. 822-827, 2005.

[23] S. Weich, M. Blanchard, M. Prince, E. Burton, B. Erens, and K. Sproston, "Mental health and the built environment: crosssectional survey of individual and contextual risk factors for depression," British Journal of Psychiatry, vol. 180, pp. 428433, 2002.

[24] C. Clark, R. Myron, and S. Stansfeld, "A systematic review of the evidence on the effect of the built and physical environment on mental health," Journal of Public Mental Health, vol. 6, no. 2, pp. 14-27, 2007.

[25] CNU, New Urban Projects on a Neighborhood Scale in the United States, New Urban News, Ithaca, NY, USA, 2002.

[26] P. Grahn and U. K. Stigsdotter, "The relation between perceived sensory dimensions of urban green space and stress restoration," Landscape and Urban Planning, vol. 94, no. 3-4, pp. 264-275, 2010.

[27] J. Maas, A. E. van den Berg, R. A. Verheij, and P. P. Groenewegen, "Green space as a buffer between stressful life events and health," Social Science and Medicine, vol. 70, no. 8, pp. 1203-1210, 2010.

[28] C. W. Thompson, "Linking landscape and health: the recurring theme," Landscape and Urban Planning, vol. 99, no. 3-4, pp. 187-195, 2011.

[29] H. Kirkpatrick and C. Byrne, "A narrative inquiry: moving on from homelessness for individuals with a major mental illness," Journal of Psychiatric and Mental Health Nursing, vol. 16 , no. 1, pp. 68-75, 2009.

[30] R. C. Kessler, T. C. Wai, O. Demler, and E. E. Walters, "Prevalence, severity, and comorbidity of 12-month DSMIV disorders in the National Comorbidity Survey Replication (NCS-R)," Archives of General Psychiatry, vol. 62, no. 6, pp. 617-627, 2005.

[31] NAMHC, From Discovery to Cure: Accelerating the Development of New and Personalized Interventions for Mental Illnesses, The National Advisory Mental Health Council, Rockville, Md, USA, 2010.

[32] R. Whitley and M. Prince, "Can urban regeneration programmes assist coping and recovery for people with mental illness? Suggestions from a qualitative case study," Health Promotion International, vol. 21, no. 1, pp. 19-26, 2006.
[33] K. Heesch, N. Burton, and W. J. Brown, "Concurrent and prospective associations between physical activity, walking and mental health in older women," Journal of Epidemiology and Community Health, vol. 65, no. 9, article 807, 2010.

[34] J. E. McHugh and B. A. Lawlor, "Exercise and social support are associated with psychological distress outcomesin a population of community-dwelling older adults," Journal of Health Psychology. In press.

[35] I. Kawachi and L. F. Berkman, "Social ties and mental health," Journal of Urban Health, vol. 78, no. 3, pp. 458-467, 2001.

[36] H. Lund, "Testing the claims of new urbanism: local access, pedestrian travel, and neighboring behaviors," Journal of the American Planning Association, vol. 69, no. 4, pp. 414-428, 2003.

[37] I. Yates, G. Holmes, and H. Priest, "There seems no place for place: a gap analysis of the recovery literature," Journal of Public Mental Health, vol. 10, no. 3, pp. 140-150, 2011.

[38] R. Morello-Frosch, M. Pastor, and J. Sadd, "Environmental justice and Southern California's "riskscape" the distribution of air toxics exposures and health risks among diverse communities," Urban Affairs Review, vol. 36, no. 4, pp. 551578, 2001.

[39] S. Wilson, M. Hutson, and M. Mujahid, "How planning and zoning contribute to inequitable development, neighborhood health, and environmental injustice," Environmental Justice, vol. 1, no. 4, pp. 211-216, 2008.

[40] B. B. Brown and D. D. Perkins, Disruptions in place attachment, in Place Attachment: Human Behavior and Environment, Plenum, New York, NY, USA, 1992.

[41] D. D. Perkins, A. Wandersman, R. C. Rich, and R. B. Taylor, "The physical environment of street crime: defensible space, territoriality and incivilities," Journal of Environmental Psychology, vol. 13, no. 1, pp. 29-49, 1993.

[42] A. Y. Akers, M. R. Muhammad, and G. Corbie-Smith, "When you got nothing to do, you do somebody': a community's perceptions of neighborhood effects on adolescent sexual behaviors," Social Science and Medicine, vol. 72, no. 1, pp. 9199, 2011.

[43] C. R. Browning, T. Leventhal, and J. Brooks-Gunn, "Neighborhood context and racial differences in early adolescent sexual activity," Demography, vol. 41, no. 4, pp. 697-720, 2004.

[44] C. Cubbin, J. Santelli, C. D. Brindis, and P. Braveman, "Neighborhood context and sexual behaviors among adolescents: findings from the National Longitudinal Study of Adolescent Health," Perspectives on Sexual and Reproductive Health, vol. 37, no. 3, pp. 125-134, 2005.

[45] CDC, Special Focus Profiles: STDs in Adolescents and Young Adults, U.S. Department of Health and Human Services, Centers for Disease Control and Prevention, Atlanta, Ga, USA, 2010.

[46] K. L. Brewster, "Neighborhood context and the transition to sexual activity among young black women," Demography, vol. 31, no. 4, pp. 603-614, 1994.

[47] D. L. Lang, L. F. Salazar, R. A. Crosby, R. J. DiClemente, L. K. Brown, and G. R. Donenberg, "Neighborhood environment, sexual risk behaviors and acquisition of sexually transmitted infections among adolescents diagnosed with psychological disorders," American Journal of Community Psychology, vol. 46, no. 3, pp. 303-311, 2010.

[48] S. J. Popkin, T. Leventhal, and G. Weismann, "Girls in the 'hood: how safety affects the life chances of low-income girls," Urban Affairs Review, vol. 45, no. 6, pp. 715-744, 2010.

[49] M. Gordon and S. Riger, The Female Fear, Free Press, New York, NY, USA, 1989. 
[50] S. J. Popkin, The Hidden War: Crime and the Tragedy of Public Housing in Chicago, Rutgers University Press, New Brunswick, NJ, USA, 2000.

[51] M. Arnold, L. Hsu, S. Pipkin, W. McFarland, and G. W. Rutherford, "Race, place and AIDS: the role of socioeconomic context on racial disparities in treatment and survival in San Francisco," Social Science and Medicine, vol. 69, no. 1, pp. 121$128,2009$.

[52] I. G. Ellen, T. Mijanovich, and K. N. Dillman, "Neighborhood effects on health: exploring the links and assessing the evidence," Journal of Urban Affairs, vol. 23, no. 3-4, pp. 391408, 2001.

[53] CDC, "New CDC Analysis Reveals Strong Link between Poverty and HIV Infection: New Study in Low-Income Heterosexuals in America's Inner Cities Reveals High HIV Rates," 2010, http://www.cdc.gov/nchhstp/newsroom/ povertyandhivpressrelease.html.

[54] C. Jencks and S. Mayer, "The social consequences of growing up in a poor neighborhood," in Inner-City Poverty in the United States, L. E. Lynn and M. F. H. McGeary, Eds., pp. 111186, National Academy Press, Washington, DC, USA, 1990.

[55] T. Leventhal and J. Brooks-Gunn, "The neighborhoods they live in: the effects of neighborhood residence on child and adolescent outcomes," Psychological Bulletin, vol. 126, no. 2, pp. 309-337, 2000.

[56] M. L. Small, Unanticipated Gains: Origins of Network Inequality in Everyday Life, Oxford University Press, New York, NY, USA, 2009.

[57] C. Watkins-Hayes, C. J. Patterson, and A. R. Armour, "Precious: black women, neighborhood HIV/AIDS risk, and institutional buffers," Du Bois Review, vol. 8, no. 1, pp. 229 240, 2011.

[58] C. Watkins-Hayes, L. Pittman, and J. Beaman, "Dying from" to "Living with" HIV/AIDS: Framing Institutions and the Coping Processes of Infected Black Women, Department of Sociology, Northwestern University, Evanston, Ill, USA, 2011.

[59] J. Eccles and J. Gootman, Community Programs to Promote Youth Development, National Academies Press, Washington, DC, USA, 2002.

[60] B. J. Hirsch, N. L. Deutsch, and D. L. Du Bois, After-School Centers and Youth Development: Case Studies of Success and Failure, Cambridge University Press, New York, NY, USA, 2011.

[61] D. Belzer, S. Srivastava, J. Wood et al., Transit-Oriented Development (TOD) and Employment, Center for Transit-Oriented Development, Oakland, Calif, USA, 2011.

[62] R. J. Chaskin and M. L. Joseph, "Building "community" in mixed-income developments: assumptions, approaches, and early experiences," Urban Affairs Review, vol. 45, no. 3, pp. 299-335, 2010.

[63] K. A. Gray and M. Galande, "Keeping "community" in a community land trust," Social Work Research, vol. 35, no. 4, pp. 241-248, 2011.

[64] M. Joseph and R. Chaskin, "Living in a mixed-income development: resident perceptions of the benefits and disadvantages of two developments in Chicago," Urban Studies, vol. 47, no. 11, pp. 2347-2366, 2010.

[65] P. E. Owens, "No teens allowed: the exclusion of adolescents from public spaces," Landscape Journal, vol. 21, pp. 156-163, 2002.

[66] D. L. McKoy and J. M. Vincent, "Engaging schools in urban revitalization: the Y-PLAN (youth-plan, learn, act, now!)," Journal of Planning Education and Research, vol. 26, no. 4, pp. 389-403, 2007.
[67] E. L. Sweet and S. O. Escalante, "Planning responds to gender violence: evidence from Spain, Mexico and the United States," Urban Studies, vol. 47, no. 10, pp. 2129-2147, 2010.

[68] C. Whitzman, M. Shaw, C. Andrew, and K. Travers, "The effectiveness of women's safety audits," Security Journal, vol. 22, no. 3, pp. 205-218, 2009.

[69] C. Andrew, "Resisting boundaries? Using safety audits for women," in Gendering the City: Women, Boundaries, and Visions of Urban Life, K. B. Miranne and A. H. Young, Eds., pp. 157-168, Rowman and Littlefied, Boston, Mass, USA, 2000.

[70] D. Satcher, The Surgeon General's Call to Action to Promote Sexual Health and Responsible Sexual Behavior, U.S. Department of Health and Human Services, Washington, DC, USA, 2001.

[71] World Health Organization, "Closing the gap in a generation: health equity through action on the social determinants of health," Final Report on the Commission on Social Determinants of Health, World Health Organization, Geneva, Switzerland, 2008. 


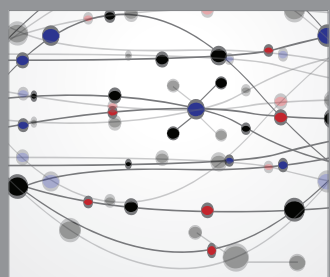

The Scientific World Journal
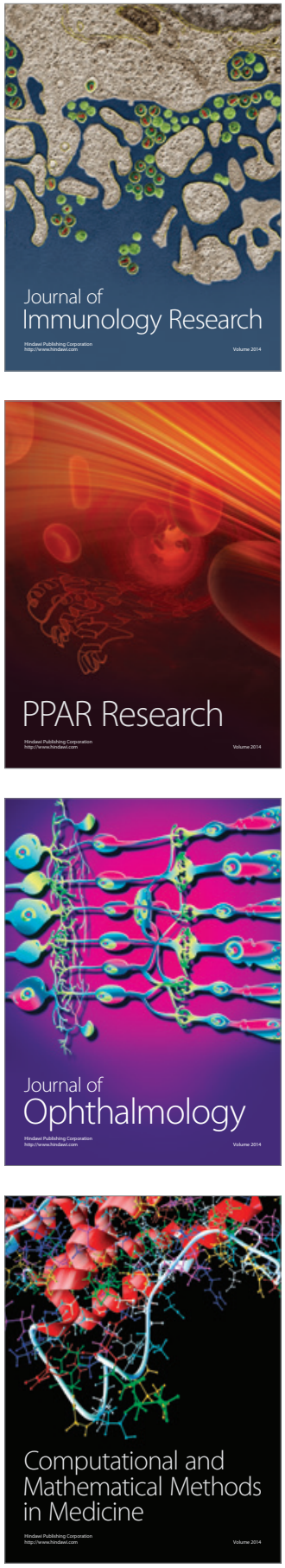

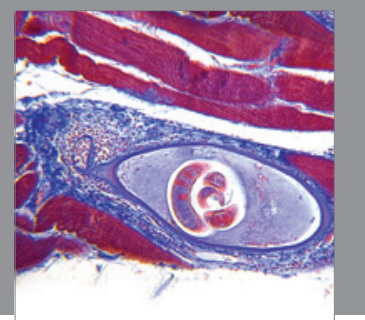

Gastroenterology

Research and Practice
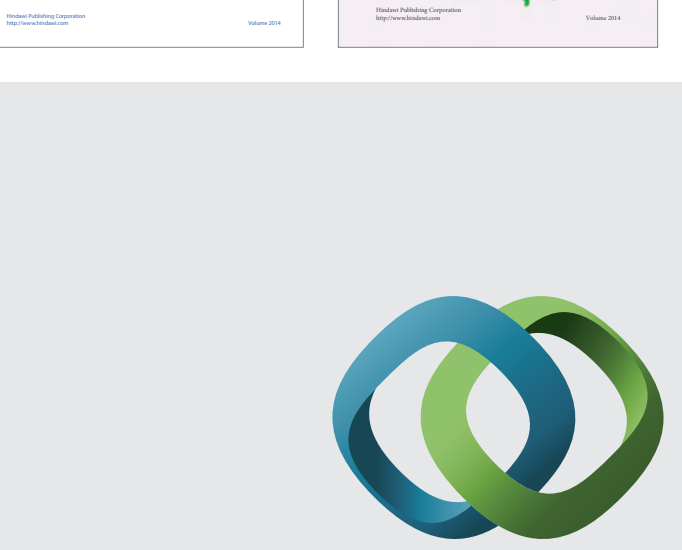

\section{Hindawi}

Submit your manuscripts at

http://www.hindawi.com




Journal of
Diabetes Research

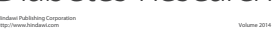

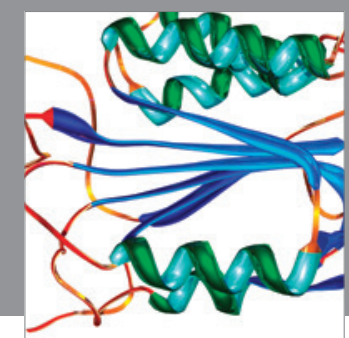

Disease Markers
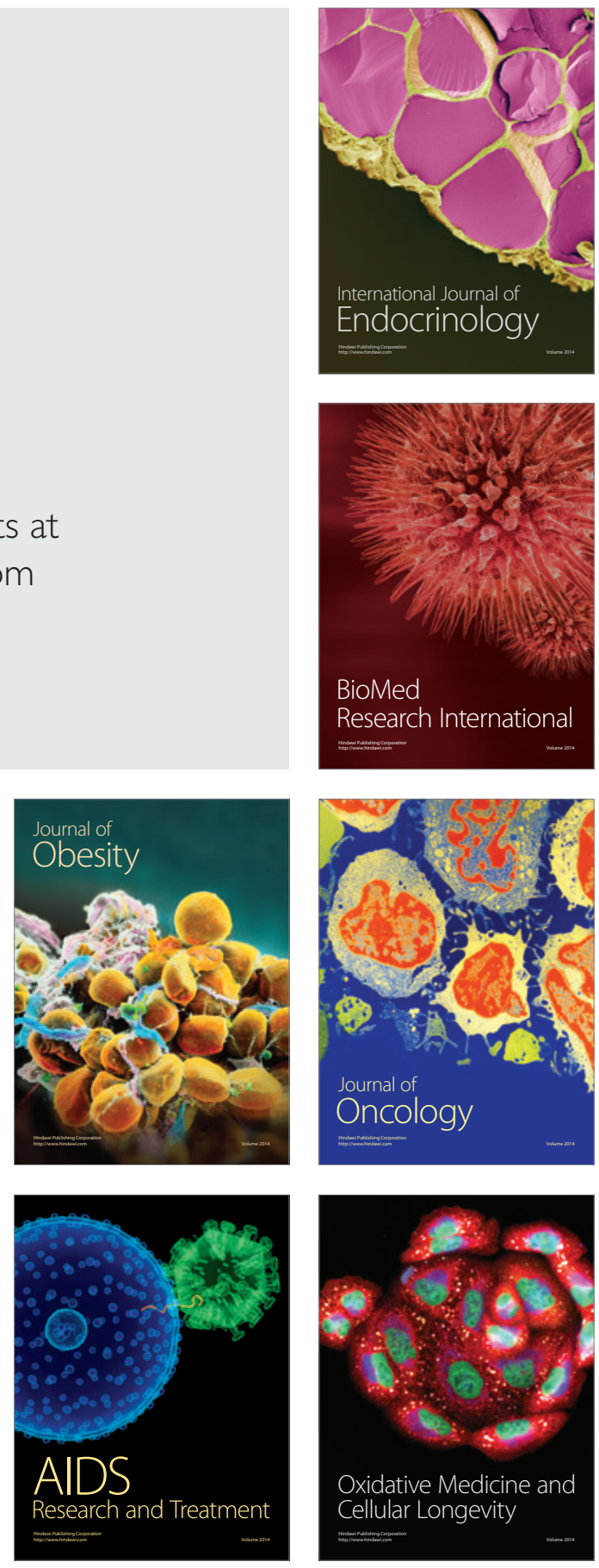